Background: Orthoses and footwear can play an important role in managing foot pathology in patients whose systemic disease is controlled. Foot orthoses are frequently prescribed in clinical practice as an intervention for people with rheumatoid arthritis (RA)

Objectives: The aim of our study is to evaluate the impact of thermoformable orthoses on the functional index of the foot (FFI) in patients with rheumatoid arthritis.

Methods: We conducted an open clinical trial, having consecutively included 14 patients $(85.7 \%$ female, average age $54.8 \pm 10$ years) suffering from rheumatoid arthritis (median progression time of 9 years [5 - 12]). The average DAS28 was $2.7 \pm 1.2$ and the functional impact objectified by the Health Assessment Questionnaire $(\mathrm{HAQ})$ was on average $0.9 \pm 0.7$.

The median deadline from the start of RA and the onset of the foot problem was 3 years $[0-7,75]$. The foot problem was bilateral in $100 \%$ of the cases and inaugural in $85.7 \%$ of the cases.

We evaluated the functional impact of foot injury for all our patients at baseline and 8 weeks after the use of thermoformable orthoses, based on the FFI (Foot function Index) measuring the impact of foot pathology on function in terms of pain, disability and activity limitation.

The comparison of the FFI domains before and after the use of orthoses was carried out using parametric or nonparametric paired tests using The SPSS statistical software.

Results: With the use of foot orthoses, FFI values decreased in all subscales $(p=0,024)$ (pain, disability and activity limitation). This reduction was significant for disability $(0,011)$ but not for pain and activity limitation.

There were no significant correlations between the global FFI and the progression of $R A$, the duration of foot damage and the functional impact measured by the HAQ.

Table 1. The comparison of the FFI domains before and after the use of orthoses.

\begin{tabular}{|c|c|c|c|c|}
\hline & & Before orthoses & After orthoses & $p$-value \\
\hline \multirow{9}{*}{ Pain scale } & When the pain was the worst & $9[5,7-10]$ & $7[4,7-8]$ & 0,09 \\
\hline & Pain in the moming & $4,5[2,2-6]$ & $2[0-3,5]$ & 0,046 \\
\hline & Pain when walking barefoot & $6[4-8]$ & $6,5[3,7-8]$ & 0,719 \\
\hline & Pain when standing barefoot & $6[3,7-7,2]$ & $6[3-7,2]$ & 0,723 \\
\hline & Pain when walking with shoes & $5[2,7-5,2]$ & $3,5[2-5,2]$ & 0,378 \\
\hline & Pain when standing with shoes & $5[2,7-6]$ & $3,5[2-5,2]$ & 0,342 \\
\hline & Pain when walking with orthoses & $0[0-0]$ & $0[0-2]$ & 0,157 \\
\hline & Pain when standing with orthoses & $0[0-0]$ & $0[0-2]$ & 0,317 \\
\hline & Pain at the end of the day & $6[4-8]$ & $3[2-5,2]$ & 0,027 \\
\hline \multirow{9}{*}{$\begin{array}{l}\text { Disability } \\
\text { scale }\end{array}$} & Difficulty walking at home & $4[3-5,2]$ & $2[0-2]$ & 0,002 \\
\hline & Difficulty walking outside & $6[4,7-7]$ & $2[1,5-2,5]$ & 0,019 \\
\hline & Difficulty walking $800 \mathrm{~m}$ & $6[3,7-7]$ & $2[1,5-2,5]$ & 0,003 \\
\hline & Difficulty climbing stairs & $5,5[3-7,2]$ & $3[1-5,2]$ & 0,032 \\
\hline & Difficulty descending stairs & $5,5[3-7,2]$ & $3[1-5,2]$ & 0,022 \\
\hline & Difficulty standing on tiptoe & $6,5[5-10]$ & $7[2,5-9,2]$ & 0,687 \\
\hline & Difficulty getting up from a chair & $5[4-6,2]$ & $3[3-5]$ & 0,032 \\
\hline & Difficulty climbing a sidewalk & $4[2-5,5]$ & $3[0-5]$ & 0,137 \\
\hline & Difficulty walking fast & $5[2,2-6]$ & $3,5[0-8]$ & 0,648 \\
\hline \multirow{5}{*}{$\begin{array}{l}\text { Activity } \\
\text { limitation }\end{array}$} & Stay all day at home & $2[1,5-5,2]$ & $0[0-2]$ & 0,077 \\
\hline & Stay all day lying down & $2[0-4]$ & $0[0-2]$ & 0,122 \\
\hline & Limitation of activities & $2[2-5]$ & $1[1-2,2]$ & 0,1 \\
\hline & Use of indoor walking aids & $0[0-0]$ & $0[0-0]$ & 1 \\
\hline & Use of walking aid outside & $0[0-0]$ & $0[0-0]$ & 0,18 \\
\hline \multicolumn{2}{|r|}{ Pain scale } & $37[32,5-47,5]$ & $36[24,5-40,5]$ & 0,198 \\
\hline \multicolumn{2}{|r|}{ Disability scale } & $49[34-59]$ & $27[13,2-46,2]$ & 0,011 \\
\hline \multicolumn{2}{|r|}{ Activity limitation } & $7[5,5-7]$ & $2,5[0-5,2]$ & 0,126 \\
\hline \multicolumn{2}{|r|}{ Total FFI score } & $95[82-106]$ & $65,5[37,5-87]$ & 0,024 \\
\hline
\end{tabular}

$p$ significatif if $<0,05$; Test used: Non-parametric test for two linked samples.

Conclusion: Foot orthoses were effective as an adjuvant in the management of rheumatoid foot. They significantly reduced disability as measured by the FFI. The absence of factors associated with pain and limitation of activity could possibly be related to the small sample size.

Disclosure of Interests: None declared

DOI: 10.1136/annrheumdis-2020-eular.6308

\section{FRI0613-HPR THE EFFECTS OF PILATES TRAINING ON RESPIRATORY MUSCLE STRENGHT IN PATIENTS WITH ANKYLOSING SPONDYLITIS}

S. Baglan Yentur ${ }^{1}$, D. C. Saraç ${ }^{2}$, F. Sari ${ }^{2}$, N. G. Tore ${ }^{2}$, H. Satış ${ }^{2}$, M. A. Ozturk², D. Oskay ${ }^{2} .{ }^{1}$ Fırat University, Elazığ, Turkey; ${ }^{2}$ Gazi Üniversity, Ankara, Turkey

Background: Ankylosing Spondylitis (AS) is a chronic, inflammatory rheumatic disease that effects primarily axial spine. Reduction in flexibility and mobility is important factors that can cause muscle weakness, impairment quality of life, reduction of exercise tolerance and pulmonary capacity with the progression of AS. Objectives: The purpose of this study was to investigate the effects of pilates exer cises on mobility, quality of life and respiratory muscle strength in patients with AS.

Methods: Forty patients with AS were randomly divided into two groups as pilates group and control group. Pilates group was performed pilates exercises and control group performed conventional exercises at home for 8 weeks, 3 days a week. Main outcome measures were maximal inspiratory pressure (MIP), maximal expiratory pressure (MEP). Secondary outcome measures were Forced Vital Capacity (FVC), Forced expiratory volume in one second/Forced Vital Capacity (FEV1/FVC), chest expansion, Bath Ankylosing Spondylitis Disease Activity Index (BASDAI), Bath Ankylosing Spondylitis Metrology Index (BASMI) and Ankylosing Spondylitis Quality of Life Questionnaire (ASQoL), 6 minutes walk test (6MWT). All participants were assessed by a blind assessor before and after the study. Results: Thirty-six AS patients $(n=19$ in the pilates group, $n=17$ in the control group) completed the study. In the pilates group, respiratory muscle strength FEV1/FVC, chest expansion, BASDAI, BASMI, ASQoL and 6MWT showed sig nificant improvements at $8^{\text {th }}$ week $(p<0.05)$, while inspiratory muscle strength FEV1/FVC, chest expansion and 6MWT showed significant improvements in the control group at $8^{\text {th }}$ week compared to baseline $(p<0.05)$. Although the pilates group had better outcomes for all parameters compared to the control group, significant differences were only observed in MIP and MEP.

Conclusion: Pilates method is an effective method for improving respiratory parameters, spinal mobility, disease activity and quality of life. Additionally, pilates training is found to be superior compared to conventional exercise training in improving respiratory muscle strength.

References:

[1] Sampaio-Barros PD, Cerqueira EMF, Rezende SM, Maeda L, Conde RA Zanardi VA et al. Pulmonary involvement in ankylosing spondylitis. Clinical rheumatology. 2007;26(2):225-30.

[2] Ozdem OY, Inanici F, Hascelik Z. Reduced vital capacity leads to exercise intolerance in patients with ankylosing spondylitis. European journal of physical and rehabilitation medicine. 2011;47(3):391-7.

[3] Altan L, Korkmaz N, Dizdar M, Yurtkuran M. Effect of Pilates training on people with ankylosing spondylitis. Rheumatology international. 2012;32(7):2093-9.

Disclosure of Interests: None declared

DOI: 10.1136/annrheumdis-2020-eular.2129

\section{FRI0614-HPR RECOMMENDATIONS FOR PATIENTS WITH RHEUMATIC DISEASES IN TREATMENT WITH METHOTREXATE}

I. Balaguer Trull ${ }^{1}$, V. Núñez-Monje ${ }^{2}$, I. Torner Hernández², A. Gómez Clari ${ }^{3}$ C. Cano ${ }^{4}$, I. Cánovas Olmos ${ }^{5}$, A. Carbonell Jordá ${ }^{6}$, J. De la Torre-Aboki ${ }^{7}$, M. D. Gil del Gallego ${ }^{8}$, E. Grau García ${ }^{5}$, M. Lorente Betoret ${ }^{4}$, E. Marín Martín ${ }^{9}$, N. Martinez Alberola $^{9}$, C. Nájera Herranz ${ }^{5}{ }^{7}$ Valencia General and University Hospital, Bone Metabolism and Rheumatology Unit, Valencia, Spain; ${ }^{2}$ Dr. Peset University Hospital, Rheumatology Unit, Valencia, Spain; ${ }^{3}$ Vinalopó University Hospital, Rheumatology Unit, Alicante, Spain; ${ }^{4}$ Marina Baixa Hospital, Rheumatology Unit, Alicante, Spain; ${ }^{5}$ La Fe University Hospital, Rheumatology Unit, Valencia, Spain; ${ }^{6}$ San Juan University Hospital, Rheumatology Unit, Alicante, Spain; ${ }^{7}$ Alicante General and University Hospital, Day Hospital, Alicante, Spain; ${ }^{8}$ Virgen de los Lirios Hospital, Rheumatology Unit, Alicante, Spain; ${ }^{9}$ Elda General and University Hospital, Rheumatology Unit, Alicante, Spain

Background: Methotrexate (MTX) is the first choice disease-modifying anti-rheumatic drug (FAME) in the treatment of rheumatoid arthritis among other rheumatic diseases. It is therefore very important that patients are aware of this treatment and have an adequate management of it.

Objectives: The development of a recommendation leaflet for patients with rheumatic diseases in treatment with MTX.

Methods: A systematic review of the literature was conducted, defining the criteria for inclusion and exclusion of content. The coordinators of the work generated preliminary recommendations that were evaluated and discussed in GESVR meetings and 10 recommendations on the use of MTX were accepted, which were later ratified by the Valencian Society of Rheumatology.

Results: The final document with a brief introduction indicates that MTX can be administered orally or subcutaneously, depending on the prescribed dose and its tolerance. In the case of subcutaneous administration, pre-filled syringes or pens are used which do not require any preparation, so there is no risk of handling and/ or inhalation toxicity. The proposed recommendations are described below:

[1] MTX should be taken or administered ONLY once a week, and always on the same day of the week. It is important to follow these recommendations to ensure adequate effectiveness and avoid side effects.

[2] It is common to add a folic acid supplement the day after MTX is taken to avoid certain side effects of the drug. In some cases it may be necessary to increase the dose to other days of the week. 
[3] Alcohol consumption should be avoided, as it increases the likelihood of adverse effects from the treatment.

[4] Common side effects include nausea or gastrointestinal distress, loss of appetite, headache and fatigue after taking each weekly dose of the drug.

If this happens, you can take the daily dose in two doses, avoid taking large amounts and drink plenty of water on the day of administration. If in spite of everything, they do not disappear, you should consult the Rheumatology Unit.

[5] It is recommended to use sun protection.

[6] Pregnancy and breastfeeding should be avoided while taking MTX. In case of pregnancy desire, you should consult the Rheumatology service in order to schedule a withdrawal of the treatment. In case of unplanned pregnancy, stop treatment and contact the Rheumatology Unit immediately.

[7] The annual flu vaccine is recommended. Consultation with the Rheumatology Unit is recommended for additional vaccines.

[8] The benefits of MTX take several weeks to appear, so you should not modify or interrupt the treatment on your own.

[9] Throughout the treatment, regular tests will be performed to monitor the safety and effectiveness of the drug.

[10] In case of doubts, and in case of infection, surgical intervention, oncological pathology or pregnancy, contact the Rheumatology Unit.

Conclusion: This leaflet is intended to resolve common doubts of patients receiving treatment with MTX, and thus contribute to improve the therapeutic adherence and avoid errors in the drug taking.

Disclosure of Interests: None declared

DOI: 10.1136/annrheumdis-2020-eular.3330

\section{FRI0615-HPR CAN DEDICATED COMMUNITY HEALTH HUBS IMPROVE PHYSICAL ACTIVITY IN A MULTI-ETHNIC RHEUMATOLOGY PRACTICE?}

J. Begum ${ }^{1}$, M. K. Nisar ${ }^{1} .^{1}$ Luton and Dunstable University Hospital, Luton, United Kingdom

Background: Self care is an important management strategy for people with inflammatory arthritis (IA). Focused education should enable people to manage their life with IA and optimise their health and well-being. Several studies have shown positive effects of dedicated health programs on a range of patient reported outcomes such as self-efficacy, pain, fatigue, quality of life and overall well-being. However these benefits are only achievable and long lasting if people are provided with professional support to stay motivated and make appropriate adjustments to obtain better health

Objectives: The objective of our intervention was to assess the outcomes of a dedicated health education program delivered in a diverse community setting represented by minorities with poor educational and socio-economic background.

Methods: We partnered with our local authority to establish a dedicated rheumatology community health hub for our patients with long term rheumatic conditions. Both clinical and paramedical staff in rheumatology clinics advertised the service and those who consented were referred. They were offered a 1:1 assessment with a health and well-being practitioner who would refer onwards based on the needs of the patient. In this pilot study we analysed the outcomes achieved at one year. Results: 187 patients were referred to the service. 158 had IA and 29 had osteoporosis. 57 (30\%) were White, 86 (46\%) Asian, 26 (14\%) Afro-Caribbean and $18(10 \%)$ of other ethnicity. Mean age was 64 years (range 36-95). Interventions included weight management $(10 \%)$, general health check $(4 \%)$, dedicated exercise program (30\%), physical activities (46\%) and talking therapies $(8 \%)$ and smoking cessation (2\%). $100 \%$ responded to the contact and signed up for the intervention. $80 \%$ completed a minimum of 12 week intervention. $89 \%$ continued to attend physical activity at least once a week long term. Only five service users dropped out for varying reasons.

Conclusion: Physical activity programs can be successful in a diverse community setting with patients from low socio-economic and educational classes. There is a need to engage these patients and offer professional support which can produce carry-over effects on physical outcomes and enhance patients' long-term adherence to such programmes. Our study demonstrates that patient activation for self management and improved physical activity can be attained irrespective of patients' backgrounds.

Disclosure of Interests: Julie Begum: None declared, Muhammad Khurram Nisar Grant/research support from: Muhammad Nisar undertakes clinical trials and received support (including attendance at conferences, speaker fees and honoraria) from Roche, Chugai, MSD, Abbvie, Pfizer, BMS, Celgene, Novartis and UCB, Consultant of: Muhammad Nisar undertakes clinical trials and received support (including attendance at conferences, speaker fees and honoraria) from Roche, Chugai, MSD, Abbvie, Pfizer, BMS, Celgene, Novartis and UCB, Speakers bureau: Muhammad Nisar undertakes clinical trials and received support (including attendance at conferences, speaker fees and honoraria) from Roche, Chugai, MSD, Abbvie, Pfizer, BMS, Celgene, Novartis and UCB DOI: 10.1136/annrheumdis-2020-eular.1988

\section{FRI0616-HPR SOCIAL SUPPORT WORKS BETTER IN RHEUMATOID} ARTHRITIS THAN FIBROMYALGIA

H. Kesmen ${ }^{1}$, A. K. Cengiz ${ }^{2}$, A. Bilgici ${ }^{2}$, G. Alayli ${ }^{2}$, D. Durmus ${ }^{2} .{ }^{1}$ Samsun Physical Medicine and Rehabilitation Hospital, Physical Medicine and Rehabilitation, Samsun, Turkey; ${ }^{2} 19$ Mayis University Faculty of Medicine, Physical Medicine and Rehabilitation, Samsun, Turkey

Background: Social support is defined as a helpful resource that can meet an individual's urgent needs and is provided by a network of others, such as family members, friends, colleagues and other communities. Perceived social support (PSS) is the subjective support that individuals may experience, emphasizing the individual's self-understanding, experience and feelings of social support from different sources. Social support directly exerts beneficial effects on the health-related quality of life in rheumatoid arthritis and fibromyalgia patients.

Objectives: The aim of this study is to compare the effect of perceived social support on quality of life of rheumatoid arthritis and fibromyalgia patients. The effect of social support from family, friends and significant others are examined separately. Methods: Fifty-eight patients with rheumatoid arthritis, fifty patients with fibromyalgia and fifty healhy controls were enrolled in the study. Short form 36 (SF-36) was used to determine the quality of life and Multidimensional Perceived Socia Support Scale (MSPSS) was used to determine the percieved social support. The effect of three factors in MSPSS (family, friends, significant others) on quality of life of rheumatoid arthritis and fibromyalgia patients were examined seperately Results: Fibromyalgia patients had lower scores than the rheumatoid arthritis patients and healthy controls regarding the physical function, pain, social functioning and mental health subscales of SF-36 $(p<0.05)$. Regarding the all MSPSS scores, there was no significant difference between the three groups $(p>0.05)$ In rheumatoid arthritis patients, MSPSS-friend and MSPSS-significant others scores were positively correlated with all subscales of SF-36. MSPSS-family score was only correlated with pain, social functioning and mental health subscales of SF-36. But in fibromyalgia patients none of the three MSPSS scores had significant correlation with SF-36 subscales (Table-1).

Conclusion: Perceived social support especially from friends and significant others, has an important positive effect on the quality of life of rheumatoid arthritis patients. For fibromyalgia patients the effect of perceived social support on quality of life is lower than that is seen in rheumatoid arthritis.

References:

[1] De Maria M, Vellone E, Durante A, Biagioli V, Matarese M. Psychometric evaluation of the Multidimensional Scale of Perceived Social Support (MSPSS) in people with chronic diseases. Ann Ist Super Sanita 2018; 54(4):308-315.

Table 1. The effect of perceived social support on quality of life in fibromyalgia and rheumatoid arthritis patients (FMS: Fibromyalgia, RA: Rheumatoid arthritis, ${ }^{*} \mathrm{p}<0.05^{* *} \mathrm{p}<0.01$ )

\begin{tabular}{lcccccc}
\hline & & $\begin{array}{c}\text { SF-36 } \\
\text { Physical functioning }\end{array}$ & $\begin{array}{c}\text { SF-36 } \\
\text { Pain }\end{array}$ & $\begin{array}{c}\text { SF-36 } \\
\text { General health }\end{array}$ & $\begin{array}{c}\text { SF-36 } \\
\text { Social functioning }\end{array}$ & $\begin{array}{c}\text { SF-36 } \\
\text { Mental } \\
\text { health }\end{array}$ \\
\hline FMS-MSPSS & $\mathrm{r}$ & -0.034 & 0.015 & -0.187 & -0.121 & -0.115 \\
Family & $\mathrm{p}$ & 0.816 & 0.915 & 0.194 & 0.401 & 0.428 \\
FMS-MSPSS & $\mathrm{r}$ & 0.154 & 0.192 & 0.221 & 0.182 & 0.089 \\
Friend & $\mathrm{p}$ & 0.285 & 0.181 & 0.123 & 0.206 & 0.539 \\
FMS-MSPSS & $\mathrm{r}$ & 0.163 & 0.248 & 0.119 & 0.175 & -0.004 \\
Significant others & $\mathrm{p}$ & 0.258 & 0.082 & 0.412 & 0.225 & 0.976 \\
RA-MSPSS & $\mathrm{r}$ & 0,181 & 0,290 & 0,225 & 0,448 & 0,340 \\
Family & $\mathrm{p}$ & 0,173 & $0,027^{*}$ & 0,089 & $0,001^{* *}$ & $0,009^{* *}$ \\
RA-MSPSS & $\mathrm{r}$ & 0,357 & 0,352 & 0,333 & 0,376 & 0,389 \\
Friend & $\mathrm{p}$ & $0,006^{*}$ & $0,007^{* *}$ & $0,011^{*}$ & $0,004^{* *}$ & $0,003^{* *}$ \\
RA-MSPSS & $\mathrm{r}$ & 0,310 & 0,310 & 0,329 & 0,315 & 0,463 \\
Significant others & $\mathrm{p}$ & $0,018^{*}$ & $0,018^{\star *}$ & $0,012^{*}$ & $0,016^{*}$ & $0,001^{*}$ \\
RA-MSPSS & $\mathrm{r}$ & 0,334 & 0,366 & 0,350 & 0,432 & 0,487 \\
Total & $\mathrm{p}$ & $0,010^{*}$ & $0,005^{* *}$ & $0,007^{* *}$ & $0,001^{* *}$ & $0,001^{* *}$ \\
FMS-MSPSS & $\mathrm{r}$ & 0.144 & 0.251 & 0.093 & 0.153 & 0.024 \\
Total & $\mathrm{p}$ & 0.320 & 0.279 & 0.519 & 0.290 & 0.867 \\
\hline
\end{tabular}

Disclosure of Interests: None declared

DOI: 10.1136/annrheumdis-2020-eular.5673

\section{FRI0617-HPR GRADED MOTOR IMAGERY IN POSTTRAUMATIC STIFFNESS OF THE ELBOW: A PILOT STUDY}

T. Birinci ${ }^{1}$, E. Kaya Mutlu ${ }^{2}$, S. Altun ${ }^{3} .{ }^{1}$ Istanbul Medeniyet University, Department of Physiotherapy and Rehabilitation, Istanbul, Turkey; ${ }^{2}$ Istanbul UniversityCerrahpasa, Department of Physiotherapy and Rehabilitation, Istanbul, Turkey; ${ }^{3}$ Bakirkoy Dr. Sadi Konuk Training and Research Hospital, Clinics of Orthopedics and Traumatology, Istanbul, Turkey

Background: Elbow fracture is treated either conservatively or surgically followed by a period of immobilization with casting or splinting. A splint used to immobilize 